\title{
Molecular Basis for the Regulation of Angiogenesis by Thrombospondin-1 and -2
}

\author{
Patrick R. Lawler ${ }^{1}$ and Jack Lawler ${ }^{2}$ \\ ${ }^{1}$ Department of Medicine, McGill University Health Center, Montreal, Quebec H3G 1Y6, Canada \\ ${ }^{2}$ Department of Pathology, Beth Israel Deaconess Medical Center; Harvard Medical School, \\ Boston, Massachusetts 02215 \\ Correspondence: jlawler@bidmc.harvard.edu
}

\begin{abstract}
Thrombospondins TSP-1 and TSP-2 are potent endogenous inhibitors of angiogenesis. They inhibit angiogenesis through direct effects on endothelial cell migration, proliferation, survival, and apoptosis and by antagonizing the activity of VEGF. Several of the membrane receptor systems and signal transduction molecules that mediate the effects of TSP-1 and TSP-2 have been elucidated. TSP-1 and TSP-2 exert their direct effects through CD36, CD47, and integrins. Recent data indicate that CD36 and $\beta 1$ integrins collaborate to transmit the signals that are initiated by TSP-1 and TSP-2. Furthermore, these receptors appear to associate with VEGFR2 to form a platform for the integration of positive and negative signals for angiogenesis. Cross talk between pro- and antiangiogenic signal transduction pathways may enable TSP-1 and TSP-2 to inhibit angiogenesis by antagonizing survival pathways while also activating apoptotic pathways. CD36 and CD47 are both involved in the suppression of nitric oxide (NO). Advances in understanding of the molecular regulation of angiogenesis by TSP have paved the way for innovations in experimental treatment of cancers and will likely continue to offer vast avenues for discovery in other disease processes as well.
\end{abstract}

In 1971, Judah Folkman proposed that the regulation of angiogenesis required endogenous inhibitors to counterbalance the effects of known stimulators (Folkman 1971). In 1990, thrombospondin-1 (TSP-1)—a 142,000-Da glycoprotein initially isolated from human platelets (Lawler et al. 1978)_became the first endogenous protein inhibitor of angiogenesis to be identified (Good et al. 1990). Noel Bouck's laboratory observed that $\mathrm{BHK} 21 / \mathrm{cl} 13$ cells secrete a $140,000-\mathrm{Da}$ factor that inhibits endothelial cell migration and neovascularization in the rat cornea. Using standard biochemical approaches, Bouck's group showed that this inhibitory factor is a proteolytic fragment of TSP-1. In the same year, Taraboletti et al. (1990) reported that TSP-1 antagonizes the growth-promoting effects of serum and basic fibroblast growth factor (bFGF) on endothelial cells, and Bagavandoss and Wilks (1990) reported that TSP-1 inhibits endothelial cell proliferation. Subsequent studies from many laboratories have identified a diverse group of proteins that inhibit angiogenesis. Some of

Editors: Michael Klagsbrun and Patricia D'Amore

Additional Perspectives on Angiogenesis available at www.perspectivesinmedicine.org

Copyright (C) 2012 Cold Spring Harbor Laboratory Press; all rights reserved; doi: 10.1101/cshperspect.a006627

Cite this article as Cold Spring Harb Perspect Med 2012;2:a006627 
these proteins, such as brain-specific angiogenesis inhibitor (BAI1), share the active sequence repeat, designated the thrombospondin type 1 repeat (TSR), with TSP-1 and TSP-2 (Kaur et al. 2003; Tucker 2004). The identification of endogenous protein inhibitors established that physiological and pathological angiogenesis is regulated by a balance of stimulators and inhibitors. It also led to the concept of the "angiogenic switch," which can be applied at the cellular or tissue level (Hanahan and Folkman 1996). On the cellular level, the "angiogenic switch" refers to the change in endothelial cell phenotype from quiescent to sprouting. The "angiogenic switch" can also refer to the changes that occur in the tumor microenvironment that lead to the initiation of angiogenesis. The amounts of TSP-1 and TSP-2 have been shown to be key determinants of the initiation of angiogenesis, and the local amount of TSP-1 in tissue is an important determinant of tumor growth (Zaslavsky et al. 2010). The identification of endogenous protein inhibitors of angiogenesis has also opened a new avenue for the development of therapeutic strategies for the regulation of angiogenesis. Recombinant protein-, small molecule-, and cell-based strategies to increase TSP levels, primarily for the treatment of cancer, are currently in development (Zhang and Lawler 2007).

The regulation of angiogenesis by TSP- 1 and TSP-2 has been extensively reviewed (Zhang and Lawler 2007; Mirochnik et al. 2008; Isenberg et al. 2009b). In the present review, we focus on the effects of TSP- 1 and TSP-2 on the molecular events in and around the endothelial cells that govern their transition to an angiogenic phenotype. These effects include suppression of vascular endothelial cell growth factor (VEGF) bioavailability and activity, induction of endothelial cell apoptosis, inhibition of endothelial cell migration, and suppression of nitric oxide signaling. We also discuss recent advances in the application of TSP-based therapies for the control of angiogenesis.

TSPs are large multidomain proteins that interact with a wide range of other proteins. As such, their functions are dynamic and pleiotropic. In some experimental models, TSP-1 has been reported to promote angiogenesis (BenEzra et al. 1993; Nicosia and Tuszynski 1994). In these models, the proangiogenic effects of TSP- 1 stem from its ability to promote the function of inflammatory cells or smooth muscle cells. In addition, the isolated aminoterminal domain of TSP-1 has been shown to promote angiogenesis (Ferrari do OuteiroBernstein et al. 2002). Although this activity is eclipsed by that of the antiangiogenic domains within the context of the intact molecule, it is possible that proteolytic cleavage of TSP-1 in tissues may generate some of this domain (Iruela-Arispe 2008).

\section{VEGF BIOAVAILABILITY AND ACTIVITY}

The antiangiogenic effects of TSP-1 have been most extensively characterized in the tumor microenvironment (Fig. 1). TSP-1 antagonizes VEGF in several important ways, via inhibition of VEGF release from the extracellular matrix, direct interaction, and inhibition of VEGF signal transduction.

In a transgenic model of breast cancer, angiogenesis, tumor size, and the level of active matrix metalloproteinase-9 (MMP-9) are inversely correlated with the level of TSP-1 (Rodriguez-Manzaneque et al. 2001). In this study, tumor progression in TSP-1-null, wild-type, and TSP-1-overexpressing mice was compared. The effect of TSP-1 on MMP-9 activation is thought to reflect the binding of TSP-1 to inactive MMP-9, which leads to suppression of activation. Similarly, cutaneous wounds in TSP-2-null mice show increased MMPs and VEGF (Maclauchlan et al. 2009). The binding of TSP-1 and TSP-2 to MMPs is mediated by the TSRs (Bein and Simons 2000). RodriguezManzaneque et al. (2001) detected decreased VEGF bound to its receptor in the presence of TSP-1. They concluded from these studies that TSP-1 inhibits the release of VEGF from the extracellular matrix through suppression of MMP activity.

TSP-1 also binds directly to VEGF, and this interaction can mediate the uptake and clearance of VEGF from the extracellular space 


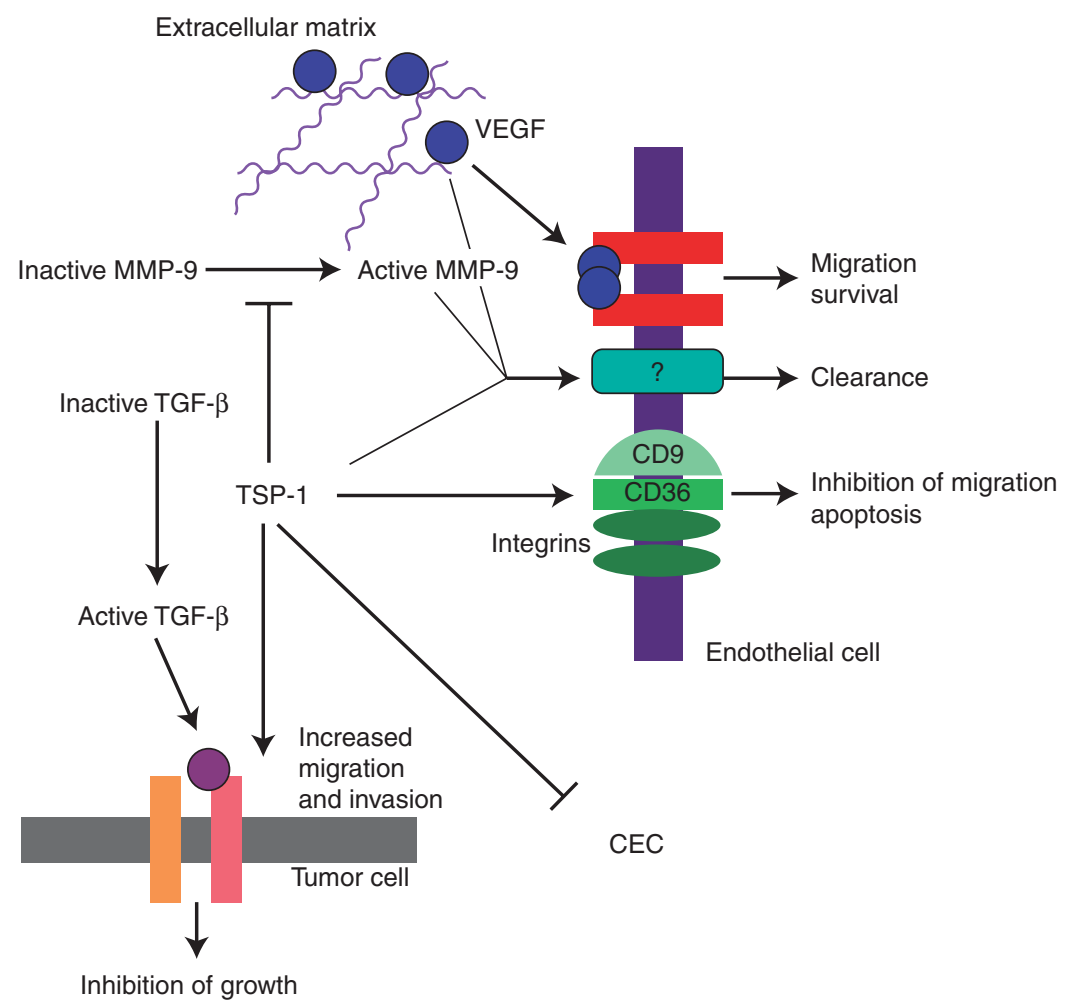

Figure 1. Schematic representation of the role of TSP-1 in the tumor microenvironment. TSP-1 affects angiogenesis through direct effects on endothelial cells and by antagonizing VEGF function. TSP-1 also suppresses the level of circulating endothelial cells (CEC).

(Gupta et al. 1999; Greenaway et al. 2007). TSP-1 binds to low-density receptor-related protein (LRP) in a glycosaminoglycan-dependent manner (Wang et al. 2004). This interaction mediates the uptake and clearance of TSP-1 along with its associated proteins. To date, MMPs and VEGF have been shown to be taken up by cells through this mechanism, which represents a second strategy for suppression of active MMPs by TSP- 1 . The domain of TSP-1 that binds to VEGF has not been identified. VEGF has, however, been reported to bind to the TSRs of other proteins, including pleiotrophin and connective tissue growth factor (Inoki et al. 2002; Heroult et al. 2004). TSP-1 binds to fibroblast growth factor-2 (FGF-2) through its type 3 repeats, and this interaction has also been proposed to inhibit angiogenesis (Colombo et al. 2010).
The three TSRs of TSP-1 have also been shown to inhibit VEGF signal transduction (Zhang et al. 2009). Treatment of human dermal microvascular endothelial cells (HDMECs) with 3TSR decreases VEGF-induced phosphorylation of VEGFR2 at tyrosine-1175 in a dosedependent fashion. Decreased VEGFR2 phosphorylation is also observed in vivo when mice are treated with 3TSR before a tail-vein injection of VEGF. This decrease in VEGFR2 phosphorylation in vivo and in vitro correlates with decreased VEGF-induced permeability as measured by the Miles assay. In these studies, the investigators also detected an interaction between VEGFR2 and CD36 (a member of the class B scavenger receptor family), which functions as a receptor for TSP-1 and TSP-2 (Zhang et al. 2009). An association of CD36 with $\beta 1$ integrins is necessary for the inhibition of 
P.R. Lawler and J. Lawler

VEGFR2 phosphorylation by TSP-1 (Primo et al. 2005). Mutation of cysteine-464 in the carboxy-terminal cytoplasmic tail of CD36 renders it incapable of complexing with $\beta 1$ integrins and of inhibiting VEGFR2 signal transduction. The close physical localization of pro- and antiangiogenic receptors in the plasma membrane may facilitate cross talk between these two signal transduction pathways.

Inhibition of VEGFR2 phosphorylation appears to lead to decreased activation of the Akt pathway. Treatment of endothelial cells with 3TSR suppresses the activation of Akt in response to VEGF (Ren et al. 2009). This observation is consistent with increased activation of survival and proliferative pathways in endothelial cells that are isolated from TSP-1-null mice (Wang et al. 2006). In addition, elevated levels of Akt phosphorylation are seen in the retinas of TSP-1-null mice (Sun et al. 2009). Because Akt mediates survival of endothelial cells, the data indicate that TSP-1 inhibits angiogenesis by antagonizing survival pathways while also activating apoptotic pathways. The absence of TSP-1 also results in an increase in the expression of fibronectin in retinal endothelial cells, which may further promote cell survival through integrin engagement (Wang et al. 2006).

\section{INDUCTION OF APOPTOSIS THROUGH CD36 AND Fyn}

In 2000, Jimenez et al. (2000) reported that TSP-1 induces apoptosis of endothelial cells in culture. Double staining with CD31 and TUNEL (terminal deoxynucleotidyl transferase dUTP nick end labeling) reveals that the TSRs of TSP-1 can induce apoptosis of tumor endothelial cells in vivo (Sun et al. 2009). In the presence of TSP-1, Fyn is recruited to CD36, and mitochondrial-dependent and -independent pathways are activated (Jimenez et al. 2000; Ren et al. 2009). In the absence of TSP-1, Src becomes the principal Src family kinase to associate with CD36 (Sun et al. 2009). The induction of endothelial cell apoptosis by TSP-1 and TSP- 2 is mediated by the binding of the TSRs to CD36 (Dawson et al. 1999; Simantov et al. 2005; Koch et al. 2011). Multiple nonoverlapping peptide sequences in the TSRs of TSP-1 have been shown to be active (IruelaArispe et al. 1999). The X-ray crystallographic structure of the TSRs revealed that they fold so that the active sequences form a single positively charged surface on one side of the domain (Tan et al. 2002). This positively charged region is thought to bind a negatively charged sequence between base pairs 95 and 143 of CD36.

A schematic representation of the signaling pathway that mediates TSP-1-induced apoptosis of endothelial cells is shown in Figure 2. Several studies have shown that activation of Jun amino-terminal kinase (JNK) occurs rapidly after TSP-1 binds to CD36 (Jimenez et al. 2001; Ren et al. 2009). TSP-1 induces apoptosis through release of cytochrome $c$ and sequential activation of caspase- 9 and caspase-3. Induction of endothelial apoptosis also involves changes in the expression of membrane receptors. Treatment of endothelial cells with TSP-1 reportedly up-regulates the Fas/FasL receptor/ ligand pair (Volpert et al. 2002). In another study, death receptors 4 and 5 were reported to be increased after treatment of endothelial cells with the TSRs (Ren et al. 2009). Whereas endothelial cells are usually resistant to tumor necrosis factor-related apoptosis-inducing ligand (TRAIL)-induced apoptosis, they become sensitized to TRAIL after treatment with 3TSR.

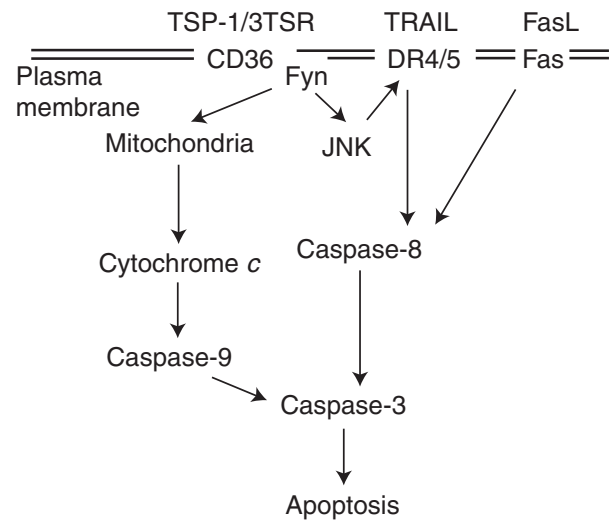

Figure 2. Signaling pathways that mediate the induction of endothelial apoptosis by TSP-1. 
Regulation of Angiogenesis by TSP-1 and TSP-2

Circulating endothelial cells (CECs) have been reported to contribute to a variable extent to tumor angiogenesis (Dome et al. 2009). The level of CECs in TSP-1-null mice is considerably higher than that of wild-type mice (Shaked et al. 2005). ABT-510 - a TSP mimetic under clinical study-decreases the number of CECs, suggesting that, like capillary endothelial cells, their survival is regulated by the interaction of the TSRs with CD36. It should be noted that it has not been established that ABT-510 binds to CD36.

\section{INHIBITION OF ENDOTHELIAL CELL MIGRATION AND PROLIFERATION}

TSP-1 reportedly inhibits angiogenesis by suppressing endothelial cell cycle progression in a CD36-independent fashion (Yamauchi et al. 2007; Oganesian et al. 2008). Very-lowdensity lipoprotein receptor (VLDLR) in the membrane of capillary endothelial cells binds TSP- 1 and mediates the inhibition of cell cycle progression through the Akt/MAPK pathway (Oganesian et al. 2008). A second pathway that includes p53 and p 21 reportedly mediates the inhibition of the cell cycle in large vessel endothelial cells (Yamauchi et al. 2007).

Endothelial cell migration is important to the formation of sprouting capillaries, and TSP-1 and TSP-2 antagonize this process (Dawson et al. 1997). The inhibition of capillary endothelial cell migration involves the binding of the TSRs to CD36 (Dawson et al. 1997). In large vessel endothelial cells, which express little or no CD36, $\beta 1$ integrins mediate the inhibition of migration through a process that involves PI3K, but not Akt (Short et al. 2005). The TSRs of TSP-1 reportedly bind multiple $\beta 1$ integrins (Calzada et al. 2004). Consistent with the close association of CD36 with $\beta 1$ integrins (see above), an antibody to the $\beta 1$ integrin subunit also suppressed the ability of TSP-1 to inhibit the migration of CD36-positive small vessel endothelial cells (Short et al. 2005). These studies cannot distinguish between effects on $\beta 1$ integrin signaling and steric hindrance of CD36 by the anti- $\beta 1$ integrin antibody because the two receptors are in close proximity.

\section{SUPPRESSION OF NITRIC OXIDE SIGNALING THROUGH CD36 AND CD47}

An important mechanism through which TSPs regulate angiogenesis is through CD36- and CD47-dependent inhibitory effects on nitric oxide (NO) (Roberts et al. 2007; Isenberg et al. 2009b). Endogenous NO is a vasoactive molecule produced primarily in the vascular endothelium using the substrate L-arginine by three isoforms of nitric oxide synthase (NOS): endothelial cell-derived NOS (eNOS; also called NOS3), macrophage-derived NOS (iNOS), and neuronal NOS (nNOS). NO signaling participates in several important vascular functions, including transient vasodilatation, inhibition of platelet aggregation, both promotion and inhibition of angiogenesis (Duda et al. 2004), and promotion of cytostasis and cell death. This spectrum of activity is explained by variations in concentration- and time-dependant actions of NO (Morbidelli et al. 2003; Roberts et al. 2007). Briefly, eNOS normally generates burst-like production of low levels $(<1-10 \mathrm{nmol} / \mathrm{L})$ of $\mathrm{NO}$, which act in a paracrine manner to relax adjacent smooth muscle cells, leading to vasodilatation. Changes in eNOS regulation (via phosphorylation of Ser-1179) lead to a more sustained, low-level production of NO (at concentrations of 1-10 $\mathrm{nmol} / \mathrm{L}$ ) that stimulates proliferation and migration of endothelial cells (Isenberg et al. 2005; Ridnour et al. 2005). NO is produced at higher levels $(>300 \mathrm{nmol} / \mathrm{L})$ by iNOS, and at these concentrations increases Ser-15 phosphorylation on p53 and phosphorylation of MKP-1, causing cytostasis and, at even higher concentrations, cell death (Isenberg et al. 2005; Ridnour et al. 2005). The variation in these effects occurs over a timescale of seconds to days, with vasodilatory and platelet effects taking place within seconds, and effects on vascular permeability and angiogenesis occurring over hours to days (Isenberg et al. 2009b).

Regulation of eNOS is complex and is achieved by altering its expression levels, posttranslational modification, subcellular localization, and binding of several regulatory proteins (Dudzinski and Michel 2007). VEGFA is an 
P.R. Lawler and J. Lawler

important driver of NO signaling via stimulation of eNOS (Murohara et al. 1998; Fukumura et al. 2001; Aicher et al. 2003; Milkiewicz et al. 2005; Yu et al. 2005). By binding its receptor VEGFR2 on the endothelial cell surface, VEGFA induces parallel pathway (via both PI3K/AKT-1 and PLCy/AMPK pathways) phosphorylation of Ser-1177 on eNOS, which drives production of NO. NO then binds to the prosthetic heme on soluble guanylate cyclase (sGC) to stimulate cyclic guanosine monophosphate (cGMP) synthesis, which acts to promote endothelial cell migration, proliferation, and survival, as well as vascular permeability (Isenberg et al. 2009b).

The relevance of VEGF-NO signaling is supported by data from eNOS-deficient mice. When type I collagen gels in the craniums of these mice were exposed to supplemental VEGFA, angiogenesis, vessel diameter, blood flow rate, and vascular permeability were found to be proportional to NO levels (Fukumura et al. 2001). TSP-1 is an important antagonist of the NO signaling pathway and powerfully counteracts these proangiogenic signals, as reviewed below. TSP-1 and TSP-2 have been shown to antagonize the proangiogenic NO signaling pathway through binding to endothelial cell surface receptors CD36 (Isenberg et al. 2007) and CD47 (Fig. 3) (Isenberg et al. 2006). Identification of NO signaling as a target of the TSP-CD36 antiangiogenic interaction was only recently proposed (Isenberg et al. 2007). Engagement of CD36 by the TSR of TSP blocks uptake of myristate and interferes with AMPK and Src signaling pathways, which are promoters of NO signaling (Fig. 3). Additionally, TSP has been shown to antagonize proangiogenic signaling by $\mathrm{NO}$ via its binding and activation of CD47 (Isenberg et al. 2009b), also known as integrin-associated protein. Whereas both CD36 and CD47 can mediate suppression of NO signaling by TSP-1, only CD47 is required (Isenberg et al. 2006). Concentrations of native TSP-1 inhibit NO signaling in vascular cells from both wild-type and CD36-null mice, suggesting simultaneous regulation of alternative NO signaling pathways by TSPs (Isenberg et al. 2006). Binding of TSP-1 to CD47 occurs at two peptide motifs on the carboxy-terminal domain (Gao et al. 1996), and although partial conservation of some of these residues is found in TSP-2 and TSP-4, high-affinity binding to CD47 appears specific to TSP-1 (Isenberg et al. 2009a). TSP-1 activates CD47, which, in turn, produces counterregulatory signals on sGC and cGMP-dependent protein kinase I (cyclic GKI, the downstream product of cGMP signaling) activity, which together interrupt proangiogenic NO signaling.

The importance of the TSP-NO pathway is supported by the observation that the inhibitory effects on angiogenesis of TSP-1 are achieved at much lower concentrations in vivo than in vitro (in assays lacking NO). Data from the studies mentioned above show that TSP-1 is a 100 -fold more potent inhibitor of angiogenesis in the presence of NO (Isenberg et al. 2005).

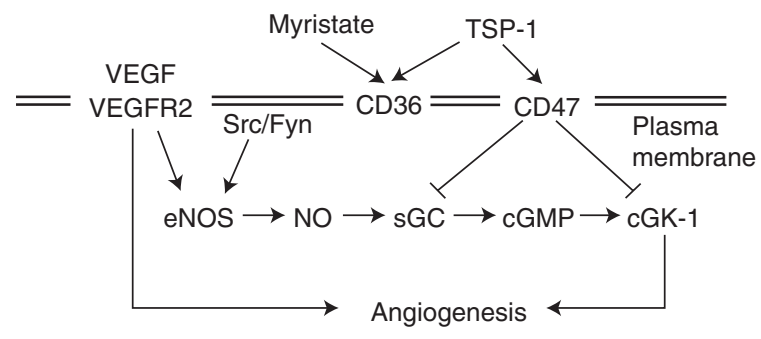

Figure 3. Inhibition of NO signaling by thrombospondin-1. TSP-1 inhibits myristate uptake by competing for binding sites on CD36. Decreased myristalation leads to decreased recruitment of Src to the plasma membrane. 
Monoclonal antibodies that interfere with VEGFR signaling-including bevacizumab, sunitinib, and sorafenib-also interrupt angiogenesis by disrupting VEGF-mediated NO signaling. Effects on NO could explain some of the known side effects of these medications, including hypertension (Izzedine et al. 2007) and thrombosis, the latter of which has been observed up to $33 \%$ more often among patients taking bevacizumab compared with placebo (Nalluri et al. 2008). Thrombospondins or their derivatives show significant promise as effective angiogenesis inhibitors and anticancer agents in animal models (Miao et al. 2001), and clinical trials are currently under way evaluating the efficacy of ABT-510 in several solid tumors. Putting the molecular effects of TSPs on NO signaling in the context of both the malignancy and the patient will be essential to identify which patients could benefit from a synthetic derivative of TSPs.

\section{THERAPEUTIC OPPORTUNITIES FOR REGULATION OF ANGIOGENESIS WITH TSP-1 AND TSP-2}

Given the importance of TSP-mediated effects on angiogenesis, apoptosis, and extracellular matrix composition, considerable interest has been shown in using this protein as a clinical therapeutic. Generally, two approaches to increasing TSP-mediated inhibition of angiogenesis have been explored in the context of neoplasia: (1) administration of chemotherapies based on recombinant TSP or a TSPderived peptide, including the TSRs of TSP-1 and TSP-2; and (2) up-regulation or potentiation of the effects of endogenous TSPs.

In contexts in which tissue ischemia limits recovery, it may be beneficial to suppress TSP expression in order to promote angiogenesis. More effective recovery is observed for kidney ischemia/reperfusion injury and the cutaneous flap assay in TSP-1-null mice as compared to wild-type mice (Thakar et al. 2005; Isenberg et al. 2007). TSP-1-null and CD47-null mice display decreased necrosis and significantly improved healing in the cutaneous flap model and full-thickness skin grafts. Whereas grafts performed onto wild-type mice fail, the majority of those performed with TSP-1-null or CD47-null mice survive (Isenberg et al. 2008). Thus, targeting the TSP-1/CD47/NO signaling axis may promote healing of skin grafts. Inhibition of TSP-1 also improves pancreatic islet graft revascularization and function (Olerud et al. 2008).

\section{Exogenous Thrombospondins and Their Derivatives}

Direct inhibition of angiogenesis through administration of therapeutic TSPs - or a derivative thereof-has been proposed as a potential anticancer therapy (Zhang and Lawler 2007). Given the complexity of its interactions, however, efforts have been undertaken to identify and purify the regions of TSP-1 and TSP-2 that interrupt angiogenesis selectively. Several domains of TSP-1 have been shown to interfere with angiogenesis, including the TSRs and procollagen homology domain (Persson et al. 1995; Guo et al. 1997; Iruela-Arispe et al. 1999; Reiher et al. 2002; Thakar et al. 2005). To illustrate this, mice with experimental B16F10 melanomas and Lewis lung carcinomas have been treated systemically with recombinant peptides composed of various combinations of the TSRs with and without the TGF- $\beta$-activating sequence of TSP-1, the RFK sequence (Miao et al. 2001). An $81 \%$ inhibition of B16F10 tumor growth was seen following treatment with a recombinant version of all three TSRs, with similar findings following administration of TSR2 + RFK (the second TSR with the TGF- $\beta$-activating sequence) recombinant protein. These peptides proved to be potent inhibitors of endothelial cell migration, and treated mice showed reduced vessel density. In addition, they had favorable effects on tumor cell apoptosis and proliferation. Similar effects on tumor inhibition were seen with a mouse model of pancreatic cancer, with decreased intratumoral vessel number and size, and increased endothelial cell apoptosis (Zhang et al. 2005). Recently, the combination of 3TSR and lexatumumab (a TRAIL receptor 2 antibody with agonist properties) has been 
P.R. Lawler and J. Lawler

shown to lead to even more potent inhibition of angiogenesis by inducing endothelial cell apoptosis and attenuating the Akt survival pathway (Ren et al. 2009), supporting the concept that synergism could accompany combination therapy. These results show promise and highlight the importance of understanding the mechanisms of TSP activity to more selectively modulate its downstream targets in favorable ways in human cancers.

Clinically, one TSP-1 mimetic-ABT-510 has been developed that is currently in clinical trials for several solid organ malignancies (Haviv et al. 2005). To date, data from phase I trials have shown a favorable toxicity profile, as well as linear and time-independent pharmacokinetics, and biologically relevant plasma concentrations, in patients with various solid organ malignancies (Hoekstra et al. 2005, 2006; Gordon et al. 2008; Nabors et al. 2010). The efficacy of ABT-510 as a single rescue agent in patients with advanced soft tissue sarcomas was recently assessed in a phase II clinical trial (Baker et al. 2008). Although the results on overall survival were encouraging, insufficient response was seen to unambiguously promote this application. Additionally, 21 patients with stage IV (metastatic) melanoma were studied in a phase II trial of ABT-510 monotherapy (Markovic et al. 2007). Similarly, this study failed to yield convincing evidence that ABT510 alone resulted in improvement in clinical outcomes. Finally, phase II data from patients with previously untreated advanced renal cell carcinoma were less ambiguous, showing no response to the study drug among patients treated with ABT-510 as a single agent (Ebbinghaus et al. 2007). All of these studies have, however, established an acceptable safety profile of the drug. Furthermore, experimental work has supported the role of ABT-510 as an adjuvant chemotherapy, which can potentiate the antitumor effects of more traditional, cytotoxic chemotherapy, including in ovarian cancer (Greenaway et al. 2009; Campbell et al. 2010). It is possible that ABT-510 specifically or other TSP mimetics will prove efficacious as an adjuvant chemotherapy, perhaps improving clinical outcomes and permitting lower exposure to more traditional cytotoxic chemotherapeutics. Clearly, more work is needed here.

\section{Strategies to Enhance the Efficacy of Exogenous Thrombospondins}

Treatment with continuous doses of antiangiogenic agents has been shown to enhance their efficacy (Kisker et al. 2001). This is true for TSPs as well (Zhang et al. 2007) and encourages strategies that could provide more sustained increases in TSP or TSP-derivative activity. Along these lines, modulation of endogenous TSP levels could provide a therapeutic avenue to increase circulating TSP levels and augment efficacy of anti-neoplastic regimens. Up-regulation of TSP-1 has been shown to be achievable with the continuous administration of low doses of chemotherapeutics, referred to as "metronomic dosing" (Browder et al. 2000), with several agents including cyclophosphamide, vinblastine, and epothilone B (Bocci et al. 2003). In the latter study, induction of gene and protein expression of TSP-1 was observed using metronomic dosing. TSP-null mice did not show an advantage in reduction of tumor burden with metronomic dosing, whereas the wild-type controls with endogenous, unadulterated TSP-1 did. Beyond changes in expression, there is a suggestion that metronomic dosing may up-regulate Fas receptor on endothelial cells and render them more susceptible to the proapoptotic effects of TSP-1 and ABT-510, particularly in the presence of other anti-neoplastic agents including cyclophosphamide and cisplatin (Yap et al. 2005). Metronomic dosing is emerging as a possible schedule to potentiate antiangiogenic effects of chemotherapeutics (Andre et al. 2010); this is an area of promise, and here, too, understanding the molecular and biochemical basis of these effects will be essential in modulating them.

\section{DELIVERY OF ANTICANCER TSP DERIVATIVES}

Cell-based delivery systems for proteins or their active domains bypass the need to prepare large quantities of purified proteins. Fibroblasts that 
overexpress TSP-2 have been incorporated into biodegradable polymer grafts and transplanted into the peritoneal cavities of mice (Streit et al. 2002). These grafts produced sustained increases in circulating TSP-2, which were able to suppress angiogenesis and growth of distant experimental squamous cell carcinoma, melanoma, and Lewis lung carcinoma.

Data from clinical trials have brought to attention several important adverse side effects associated with angiogenesis inhibitors, including hypertension and thromboembolic events associated with bevacizumab (Nalluri et al. 2008). Clinical studies evaluating ABT-510 to date have been insufficiently powered to identify important adverse effects. Nevertheless, what is clear is that targeted, sustained delivery of anti-tumor agents to the tumor microenvironment would intuitively result in better tumor inhibition with fewer systemic side effects. Recently, mesenchymal stem cells (MSCs) have emerged as novel cell-based delivery agents to achieve these ends (Aboody et al. 2008; Sasportas et al. 2009), and data from TSP-expressing cell lines in central nervous system gliomas are encouraging. Human malignant astrocytomas (including glioblastoma multiforme) are associated with a poor prognosis, and therapeutic options are very limited at the present time. These are vascular tumors, for which angiogenesis has been shown to be a critical component, and antiangiogenic therapy looked upon as a ray of hope for treatment of these cancers (Chi et al. 2009a,b). ABT-510 has been shown experimentally to be effective in reducing malignant glioma neovascularization and inhibiting tumor growth (Anderson et al. 2007), making it an attractive target for MSC delivery. Recently, human neural stem cells (hNSCs) have been used experimentally to provide sustained on-site delivery of secretable TSR protein to highly malignant human gliomas raised in mice (van Eekelen et al. 2010). Treatment with a single dose of 3TSR-bearing hNSCs induced a significant reduction in tumor vessel density that resulted in inhibition of tumor progression and was accompanied by a survival benefit in these mice. Mesenchymal stem cells and other innovative strategies for more effective TSP delivery show considerable promise and will likely continue to be an area of interest among researchers and clinicians.

\section{FUTURE DIRECTIONS}

Initial data indicate that TSP-1 and TSP-2 bind to multiple membrane proteins and direct the assembly of complexes that affect signal transduction pathways that regulate cell survival, migration, differentiation, and growth. The formation of these multiprotein complexes may serve to colocalize receptor systems to specific regions of the membrane, such as lipid rafts and tetraspanin-enriched microdomains, where signal transduction can efficiently proceed (Chen et al. 2000; Hynes 2009). The ability to recruit and organize the constituents of these multiprotein complexes may be key to the effects of TSP-1 and TSP-2 on cellular behavior during dynamic processes such as angiogenesis. Future studies will elucidate the composition of these complexes and their function in controlling endothelial cell phenotype. They will also elucidate the role of specific signal transduction pathways in the regulation of angiogenesis by TSPs.

Therapeutic interventions that either downregulate or up-regulate TSP levels to promote or inhibit angiogenesis, respectively, may prove useful in the future. Humanized antibodies are a proven way to antagonize endogenous proteins. Topical application of antibodies to TSP-1, TSP-2, and CD47 could be developed to promote the grafting of skin. Because producing large quantities of protein therapeutics is challenging, cell-based therapies for localized or systemic up-regulation of TSP expression are attractive. It is also possible that small molecules that regulate endogenous TSP expression could be developed for topical or systemic administration. Because cancer and cardiovascular disease remain the two most common causes of death in developed nations, development in innovative therapeutic strategies to modulate angiogenesis favorably (pro- in the latter, anti- in the former) will likely continue for many years to come and promises to be a fascinating voyage of discovery. 
P.R. Lawler and J. Lawler

\section{ACKNOWLEDGMENTS}

We thank Raji Bhat and Sami Lawler for help in preparing the manuscript. This work was supported by grant CA130895 from the National Cancer Institute of the National Institutes of Health.

\section{REFERENCES}

Aboody KS, Najbauer J, Danks MK. 2008. Stem and progenitor cell-mediated tumor selective gene therapy. Gene Ther 15: 739-752.

Aicher A, Heeschen C, Mildner-Rihm C, Urbich C, Ihling C, Technau-Ihling K, Zeiher AM, Dimmeler S. 2003. Essential role of endothelial nitric oxide synthase for mobilization of stem and progenitor cells. Nat Med 9: 1370-1376.

Anderson JC, Grammer JR, Wang W, Nabors LB, Henkin J, Stewart JE Jr, Gladson CL. 2007. ABT-510, a modified type 1 repeat peptide of thrombospondin, inhibits malignant glioma growth in vivo by inhibiting angiogenesis. Cancer Biol Ther 6: 454-462.

Andre N, Padovani L, Verschuur A. 2010. Metronomic chemotherapy: Back to the future! Drug News Perspect 23: 143-151.

Bagavandoss P, Wilks JW. 1990. Specific inhibition of endothelial cell proliferation by thrombospondin. Biochem Biophys Res Commun 170: 867-872.

Baker LH, Rowinsky EK, Mendelson D, Humerickhouse RA, Knight RA, Qian J, Carr RA, Gordon GB, Demetri GD. 2008. Randomized, phase II study of the thrombospondin-1-mimetic angiogenesis inhibitor ABT-510 in patients with advanced soft tissue sarcoma. J Clin Oncol 26: $5583-5588$.

Bein K, Simons M. 2000. Thrombospondin type 1 repeats interact with matrix metalloproteinase 2. Regulation of metalloproteinase activity. J Biol Chem 275: 3216732173.

BenEzra D, Griffin BW, Maftzir G, Aharonov O. 1993. Thrombospondin and in vivo angiogenesis induced by basic fibroblast growth factor or lipopolysaccharide. Invest Ophthalmol Vis Sci 34: 3601-3608.

Bocci G, Francia G, Man S, Lawler J, Kerbel RS. 2003. Thrombospondin 1, a mediator of the antiangiogenic effects of low-dose metronomic chemotherapy. Proc Natl Acad Sci 100: 12917-12922.

Browder T, Butterfield CE, Kraling BM, Shi B, Marshall B, O’Reilly MS, Folkman J. 2000. Antiangiogenic scheduling of chemotherapy improves efficacy against experimental drug-resistant cancer. Cancer Res 60: 1878-1886.

Calzada MJ, Annis DS, Zeng B, Marcinkiewicz C, Banas B, Lawler J, Mosher DF, Roberts DD. 2004. Identification of novel $\beta_{1}$ integrin binding sites in the type 1 and type 2 repeats of thrombospondin-1. J Biol Chem 279: 41734-41743.

Campbell NE, Greenaway J, Henkin J, Moorehead RA, Petrik J. 2010. The thrombospondin-1 mimetic ABT-510 increases the uptake and effectiveness of cisplatin and paclitaxel in a mouse model of epithelial ovarian cancer. Neoplasia 12: 275-283.

Chen H, Herndon ME, Lawler J. 2000. The cell biology of thrombospondin-1. Matrix Biol 19: 597-614.

Chi AS, Norden AD, Wen PY. 2009a. Antiangiogenic strategies for treatment of malignant gliomas. Neurotherapeutics 6: 513-526.

Chi AS, Sorensen AG, Jain RK, Batchelor TT. 2009b. Angiogenesis as a therapeutic target in malignant gliomas. Oncologist 14: 621-636.

Colombo G, Margosio B, Ragona L, Neves M, Bonifacio S, Annis DS, Stravalaci M, Tomaselli S, Giavazzi R, Rusnati $\mathrm{M}$, et al. 2010. Non-peptidic thrombospondin-1 mimics as fibroblast growth factor-2 inhibitors: An integrated strategy for the development of new antiangiogenic compounds. J Biol Chem 285: 8733-8742.

Dawson DW, Pearce SF, Zhong R, Silverstein RL, Frazier WA, Bouck NP. 1997. CD36 mediates the in vitro inhibitory effects of thrombospondin-1 on endothelial cells. J Cell Biol 138: 707-717.

Dawson DW, Volpert OV, Pearce SF, Schneider AJ, Silverstein RL, Henkin J, Bouck NP. 1999. Three distinct D-amino acid substitutions confer potent antiangiogenic activity on an inactive peptide derived from a thrombospondin-1 type 1 repeat. Mol Pharmacol 55: 332-338.

Dome B, Timar J, Ladanyi A, Paku S, Renyi-Vamos F, Klepetko W, Lang G, Dome P, Bogos K, Tovari J. 2009. Circulating endothelial cells, bone marrow-derived endothelial progenitor cells and proangiogenic hematopoietic cells in cancer: From biology to therapy. Crit Rev Oncol Hematol 69: $108-124$.

Duda DG, Fukumura D, Jain RK. 2004. Role of eNOS in neovascularization: $\mathrm{NO}$ for endothelial progenitor cells. Trends Mol Med 10: 143-145.

Dudzinski DM, Michel T. 2007. Life history of eNOS: Partners and pathways. Cardiovasc Res 75: 247-260.

Ebbinghaus S, Hussain M, Tannir N, Gordon M, Desai AA, Knight RA, Humerickhouse RA, Qian J, Gordon GB, Figlin R. 2007. Phase 2 study of ABT-510 in patients with previously untreated advanced renal cell carcinoma. Clin Cancer Res 13: 6689-6695.

Ferrari do Outeiro-Bernstein MA, Nunes SS, Andrade AC, Alves TR, Legrand C, Morandi V. 2002. A recombinant $\mathrm{NH}_{2}$-terminal heparin-binding domain of the adhesive glycoprotein, thrombospondin-1, promotes endothelial tube formation and cell survival: A possible role for syndecan-4 proteoglycan. Matrix Biol 21: 311-324.

Folkman J. 1971. Tumor angiogenesis: Therapeutic implications. N Engl J Med 285: 1182-1186.

Fukumura D, Gohongi T, Kadambi A, Izumi Y, Ang J, Yun CO, Buerk DG, Huang PL, Jain RK. 2001. Predominant role of endothelial nitric oxide synthase in vascular endothelial growth factor-induced angiogenesis and vascular permeability. Proc Natl Acad Sci 98: 2604-2609.

Gao AG, Lindberg FP, Finn MB, Blystone SD, Brown EJ, Frazier WA. 1996. Integrin-associated protein is a receptor for the C-terminal domain of thrombospondin. J Biol Chem 271: 21-24.

Good DJ, Polverini PJ, Rastinejad F, Le Beau MM, Lemons RS, Frazier WA, Bouck NP. 1990. A tumor suppressordependent inhibitor of angiogenesis is immunologically 
and functionally indistinguishable from a fragment of thrombospondin. Proc Natl Acad Sci 87: 6624-6628.

Gordon MS, Mendelson D, Carr R, Knight RA, Humerickhouse RA, Iannone M, Stopeck AT. 2008. A phase 1 trial of 2 dose schedules of ABT-510, an antiangiogenic, thrombospondin-1-mimetic peptide, in patients with advanced cancer. Cancer 113: 3420-3429.

Greenaway J, Lawler J, Moorehead R, Bornstein P, Lamarre J, Petrik J. 2007. Thrombospondin-1 inhibits VEGF levels in the ovary directly by binding and internalization via the low density lipoprotein receptor-related protein-1 (LRP-1). J Cell Physiol 210: 807-818.

Greenaway J, Henkin J, Lawler J, Moorehead R, Petrik J. 2009. ABT-510 induces tumor cell apoptosis and inhibits ovarian tumor growth in an orthotopic, syngeneic model of epithelial ovarian cancer. Mol Cancer Ther 8: 64-74.

Guo NH, Krutzsch HC, Inman JK, Shannon CS, Roberts DD. 1997. Antiproliferative and antitumor activities of D-reverse peptides derived from the second type-1 repeat of thrombospondin-1. J Pept Res 50: 210-221.

Gupta K, Gupta P, Wild R, Ramakrishnan S, Hebbel RP. 1999. Binding and displacement of vascular endothelial growth factor (VEGF) by thrombospondin: Effect on human microvascular endothelial cell proliferation and angiogenesis. Angiogenesis 3: 147-158.

Hanahan D, Folkman J. 1996. Patterns and emerging mechanisms of the angiogenic switch during tumorigenesis. Cell 86: 353-364.

Haviv F, Bradley MF, Kalvin DM, Schneider AJ, Davidson DJ, Majest SM, McKay LM, Haskell CJ, Bell RL, Nguyen B, et al. 2005. Thrombospondin-1 mimetic peptide inhibitors of angiogenesis and tumor growth: Design, synthesis, and optimization of pharmacokinetics and biological activities. J Med Chem 48: 2838-2846.

Heroult M, Bernard-Pierrot I, Delbe J, Hamma-Kourbali Y, Katsoris P, Barritault D, Papadimitriou E, Plouet J, Courty J. 2004. Heparin affin regulatory peptide binds to vascular endothelial growth factor (VEGF) and inhibits VEGF-induced angiogenesis. Oncogene 23: $1745-1753$.

Hoekstra R, de Vos FY, Eskens FA, Gietema JA, van der Gaast A, Groen HJ, Knight RA, Carr RA, Humerickhouse RA, Verweij J, et al. 2005. Phase I safety, pharmacokinetic, and pharmacodynamic study of the thrombospondin-1mimetic angiogenesis inhibitor ABT-510 in patients with advanced cancer. J Clin Oncol 23: 5188-5197.

Hoekstra R, de Vos FY, Eskens FA, de Vries EG, Uges DR, Knight R, Carr RA, Humerickhouse R, Verweij J, Gietema JA. 2006. Phase I study of the thrombospondin-1mimetic angiogenesis inhibitor ABT-510 with 5fluorouracil and leucovorin: A safe combination. Eur $J$ Cancer 42: 467-472.

Hynes RO. 2009. The extracellular matrix: Not just pretty fibrils. Science 326: 1216-1219.

Inoki I, Shiomi T, Hashimoto G, Enomoto H, Nakamura H, Makino K, Ikeda E, Takata S, Kobayashi K, Okada Y. 2002. Connective tissue growth factor binds vascular endothelial growth factor (VEGF) and inhibits VEGF-induced angiogenesis. FASEB J 16: 219-221.

Iruela-Arispe ML. 2008. Regulation of thrombospondin1 by extracellular proteases. Curr Drug Targets 9: 863-868.
Iruela-Arispe ML, Lombardo M, Krutzsch HC, Lawler J, Roberts DD. 1999. Inhibition of angiogenesis by thrombospondin- 1 is mediated by 2 independent regions within the type 1 repeats. Circulation 100: 1423-1431.

Isenberg JS, Ridnour LA, Perruccio EM, Espey MG, Wink DA, Roberts DD. 2005. Thrombospondin-1 inhibits endothelial cell responses to nitric oxide in a cGMPdependent manner. Proc Natl Acad Sci 102: 1314113146.

Isenberg JS, Ridnour LA, Dimitry J, Frazier WA, Wink DA, Roberts DD. 2006. CD47 is necessary for inhibition of nitric oxide-stimulated vascular cell responses by thrombospondin-1. J Biol Chem 281: 26069-26080.

Isenberg JS, Jia Y, Fukuyama J, Switzer CH, Wink DA, Roberts DD. 2007. Thrombospondin-1 inhibits nitric oxide signaling via CD36 by inhibiting myristic acid uptake. $J$ Biol Chem 282: 15404-15415.

Isenberg JS, Pappan LK, Romeo MJ, Abu-Asab M, Tsokos M, Wink DA, Frazier WA, Roberts DD. 2008. Blockade of thrombospondin-1-CD47 interactions prevents necrosis of full thickness skin grafts. Ann Surg 247: $180-190$.

Isenberg JS, Annis DS, Pendrak ML, Ptaszynska M, Frazier WA, Mosher DF, Roberts DD. 2009a. Differential interactions of thrombospondin-1, -2, and -4 with CD47 and effects on cGMP signaling and ischemic injury responses. J Biol Chemo 284: 1116-1125.

Isenberg JS, Martin-Manso G, Maxhimer JB, Roberts DD. 2009b. Regulation of nitric oxide signaling by thrombospondin 1: Implications for anti-angiogenic therapies. Nat Rev Cancer 9: 182-194.

Izzedine $\mathrm{H}$, Rixe O, Billemont B, Baumelou A, Deray G. 2007. Angiogenesis inhibitor therapies: Focus on kidney toxicity and hypertension. Am J Kidney Dis 50: 203-218.

Jimenez B, Volpert OV, Crawford SE, Febbraio M, Silverstein RL, Bouck N. 2000. Signals leading to apoptosisdependent inhibition of neovascularization by thrombospondin-1. Nat Med 6: 41-48.

Jimenez B, Volpert OV, Reiher F, Chang L, Munoz A, Karin M, Bouck N. 2001. c-Jun N-terminal kinase activation is required for the inhibition of neovascularization by thrombospondin-1. Oncogene 20: 3443-3448.

Kaur B, Brat DJ, Calkins CC, Van Meir EG. 2003. Brain angiogenesis inhibitor 1 is differentially expressed in normal brain and glioblastoma independently of p53 expression. Am J Pathol 162: 19-27.

Kisker O, Becker CM, Prox D, Fannon M, D'Amato R, Flynn E, Fogler WE, Sim BK, Allred EN, Pirie-Shepherd, et al. 2001. Continuous administration of endostatin by intraperitoneally implanted osmotic pump improves the efficacy and potency of therapy in a mouse xenograft tumor model. Cancer Res 61: 7669-7674.

Koch M, Hussein F, Woeste A, Grundker C, Frontzek K, Emons G, Hawighorst T. 2011. CD36-mediated activation of endothelial cell apoptosis by an N-terminal recombinant fragment of thrombospondin-2 inhibits breast cancer growth and metastasis in vivo. Breast Cancer Res Treat 128: 337-346.

Lawler JW, Slayter HS, Coligan JE. 1978. Isolation and characterization of a high molecular weight glycoprotein from human blood platelets. J Biol Chem 253: 86098616. 
P.R. Lawler and J. Lawler

Maclauchlan S, Skokos EA, Agah A, Zeng J, Tian W, Davidson JM, Bornstein P, Kyriakides TR. 2009. Enhanced angiogenesis and reduced contraction in thrombospondin-2-null wounds is associated with increased levels of matrix metalloproteinases-2 and -9, and soluble VEGF. J Histochem Cytochem 57: 301-313.

Markovic SN, Suman VJ, Rao RA, Ingle JN, Kaur JS, Erickson LA, Pitot HC, Croghan GA, McWilliams RR, Merchan J, et al. 2007. A phase II study of ABT-510 (thrombospondin-1 analog) for the treatment of metastatic melanoma. Am J Clin Oncol 30: 303-309.

Miao WM, Seng WL, Duquette M, Lawler P, Laus C, Lawler J. 2001. Thrombospondin-1 type 1 repeat recombinant proteins inhibit tumor growth through transforming growth factor- $\beta$-dependent and -independent mechanisms. Cancer Res 61: 7830-7839.

Milkiewicz M, Hudlicka O, Brown MD, Silgram H. 2005. Nitric oxide, VEGF, and VEGFR-2: Interactions in activity-induced angiogenesis in rat skeletal muscle. $A m$ J Physiol Heart Circ Physiol 289: H336-H343.

Mirochnik Y, Kwiatek A, Volpert OV. 2008. Thrombospondin and apoptosis: Molecular mechanisms and use for design of complementation treatments. Curr Drug Targets 9: 851-862.

Morbidelli L, Donnini S, Ziche M. 2003. Role of nitric oxide in the modulation of angiogenesis. Curr Pharm Des 9: 521-530.

Murohara T, Asahara T, Silver M, Bauters C, Masuda H, Kalka C, Kearney M, Chen D, Symes JF, Fishman MC, et al. 1998. Nitric oxide synthase modulates angiogenesis in response to tissue ischemia. J Clin Invest 101: 2567-2578.

Nabors LB, Fiveash JB, Markert JM, Kekan MS, Gillespie GY, Huang Z, Johnson MJ, Meleth S, Kuo H, Gladson CL, et al. 2010. A phase 1 trial of ABT-510 concurrent with standard chemoradiation for patients with newly diagnosed glioblastoma. Arch Neurol 67: 313-319.

Nalluri SR, Chu D, Keresztes R, Zhu X, Wu S. 2008. Risk of venous thromboembolism with the angiogenesis inhibitor bevacizumab in cancer patients: A meta-analysis. JAMA 300: 2277-2285.

Nicosia RF, Tuszynski GP. 1994. Matrix-bound thrombospondin promotes angiogenesis in vitro. J Cell Biol 124: 183-193.

Oganesian A, Armstrong LC, Migliorini MM, Strickland DK, Bornstein P. 2008. Thrombospondins use the VLDL receptor and a nonapoptotic pathway to inhibit cell division in microvascular endothelial cells. Mol Biol Cell 19: 563-571.

Olerud J, Johansson M, Lawler J, Welsh N, Carlsson PO. 2008. Improved vascular engraftment and graft function after inhibition of the angiostatic factor thrombospondin-1 in mouse pancreatic islets. Diabetes 57: 1870-1877.

Persson T, Lanshammar H, Medved V. 1995. A marker-free method to estimate joint centre of rotation by video image processing. Comput Methods Programs Biomed 46: $217-224$.

Primo L, Ferrandi C, Roca C, Marchio S, di Blasio L, Alessio M, Bussolino F. 2005. Identification of CD36 molecular features required for its in vitro angiostatic activity. FASEB J 19: 1713-1715.
Reiher FK, Volpert OV, Jimenez B, Crawford SE, Dinney CP, Henkin J, Haviv F, Bouck NP, Campbell SC. 2002. Inhibition of tumor growth by systemic treatment with thrombospondin-1 peptide mimetics. Int J Cancer 98: $682-689$.

Ren B, Song K, Parangi S, Jin T, Ye M, Humphreys R, Duquette M, Zhang X, Benhaga N, Lawler J, Khosravi-Far R. 2009. A double hit to kill tumor and endothelial cells by TRAIL and antiangiogenic 3TSR. Cancer Res 69: 3856-3865.

Ridnour LA, Isenberg JS, Espey MG, Thomas DD, Roberts DD, Wink DA. 2005. Nitric oxide regulates angiogenesis through a functional switch involving thrombospondin1. Proc Natl Acad Sci 102: 13147-13152.

Roberts DD, Isenberg JS, Ridnour LA, Wink DA. 2007. Nitric oxide and its gatekeeper thrombospondin-1 in tumor angiogenesis. Clin Cancer Res 13: 795-798.

Rodriguez-Manzaneque JC, Lane TF, Ortega MA, Hynes RO, Lawler J, Iruela-Arispe ML. 2001. Thrombospondin-1 suppresses spontaneous tumor growth and inhibits activation of matrix metalloproteinase- 9 and mobilization of vascular endothelial growth factor. Proc Natl Acad Sci 98: 12485-12490.

Sasportas LS, Kasmieh R, Wakimoto H, Hingtgen S, van de Water JA, Mohapatra G, Figueiredo JL, Martuza RL, Weissleder R, Shah K. 2009. Assessment of therapeutic efficacy and fate of engineered human mesenchymal stem cells for cancer therapy. Proc Natl Acad Sci 106: 4822-4827.

Shaked Y, Bertolini F, Man S, Rogers MS, Cervi D, Foutz T, Rawn K, Voskas D, Dumont DJ, Ben-David Y, et al. 2005. Genetic heterogeneity of the vasculogenic phenotype parallels angiogenesis: Implications for cellular surrogate marker analysis of antiangiogenesis. Cancer Cell 7: $101-111$.

Short SM, Derrien A, Narsimhan RP, Lawler J, Ingber DE, Zetter BR. 2005. Inhibition of endothelial cell migration by thrombospondin-1 type- 1 repeats is mediated by beta1 integrins. J Cell Biol 168: 643-653.

Simantov R, Febbraio M, Silverstein RL. 2005. The antiangiogenic effect of thrombospondin-2 is mediated by CD36 and modulated by histidine-rich glycoprotein. Matrix Biol 24: 27-34.

Streit M, Stephen AE, Hawighorst T, Matsuda K, Lange-Asschenfeldt B, Brown LF, Vacanti JP, Detmar M. 2002. Systemic inhibition of tumor growth and angiogenesis by thrombospondin-2 using cell-based antiangiogenic gene therapy. Cancer Res 62: 2004-2012.

Sun J, Hopkins BD, Tsujikawa K, Perruzzi C, Adini I, Swerlick R, Bornstein P, Lawler J, Benjamin LE. 2009. Thrombospondin-1 modulates VEGF-A-mediated Akt signaling and capillary survival in the developing retina. Am J Physiol Heart Circ Physiol 296: H1344-H1351.

Tan K, Duquette M, Liu JH, Dong Y, Zhang R, Joachimiak A, Lawler J, Wang JH. 2002. Crystal structure of the TSP-1 type 1 repeats: A novel layered fold and its biological implication. J Cell Biol 159: 373-382.

Taraboletti G, Roberts D, Liotta LA, Giavazzi R. 1990. Platelet thrombospondin modulates endothelial cell adhesion, motility, and growth: A potential angiogenesis regulatory factor. J Cell Biol 111: 765-772. 
Thakar CV, Zahedi K, Revelo MP, Wang Z, Burnham CE, Barone S, Bevans S, Lentsch AB, Rabb H, Soleimani M. 2005. Identification of thrombospondin 1 (TSP-1) as a novel mediator of cell injury in kidney ischemia. J Clin Invest 115: 3451-3459.

Tucker RP. 2004. The thrombospondin type 1 repeat superfamily. Int J Biochem Cell Biol 36: 969-974.

van Eekelen M, Sasportas LS, Kasmieh R, Yip S, Figueiredo JL, Louis DN, Weissleder R, Shah K. 2010. Human stem cells expressing novel TSP-1 variant have anti-angiogenic effect on brain tumors. Oncogene 29: 3185-3195.

Volpert OV, Zaichuk T, Zhou W, Reiher F, Ferguson TA, Stuart PM, Amin M, Bouck NP. 2002. Inducerstimulated Fas targets activated endothelium for destruction by anti-angiogenic thrombospondin- 1 and pigment epithelium-derived factor. Nat Med 8: 349-357.

Wang S, Herndon ME, Ranganathan S, Godyna S, Lawler J, Argraves WS, Liau G. 2004. Internalization but not binding of thrombospondin-1 to low density lipoprotein receptor-related protein-1 requires heparan sulfate proteoglycans. J Cell Biochem 91: 766-776.

Wang Y, Wang S, Sheibani N. 2006. Enhanced proangiogenic signaling in thrombospondin-1-deficient retinal endothelial cells. Microvasc Res 71: 143-151.

Yamauchi M, Imajoh-Ohmi S, Shibuya M. 2007. Novel antiangiogenic pathway of thrombospondin-1 mediated by suppression of the cell cycle. Cancer Sci 98: 1491-1497.

Yap R, Veliceasa D, Emmenegger U, Kerbel RS, McKay LM, Henkin J, Volpert OV. 2005. Metronomic low-dose chemotherapy boosts CD95-dependent antiangiogenic effect of the thrombospondin peptide ABT-510: A complementation antiangiogenic strategy. Clin Cancer Res 11: 6678-6685.

Yu J, deMuinck ED, Zhuang Z, Drinane M, Kauser K, Rubanyi GM, Qian HS, Murata T, Escalante B, Sessa WC. 2005. Endothelial nitric oxide synthase is critical for ischemic remodeling, mural cell recruitment, and blood flow reserve. Proc Natl Acad Sci 102: 10999-11004.

Zaslavsky A, Chen C, Grillo J, Baek KH, Holmgren L, Yoon SS, Folkman J, Ryeom S. 2010. Regional control of tumor growth. Mol Cancer Res 8: 1198-1206.

Zhang X, Lawler J. 2007. Thrombospondin-based antiangiogenic therapy. Microvasc Res 74: 90-99.

Zhang X, Galardi E, Duquette M, Delic M, Lawler J, Parangi S. 2005. Antiangiogenic treatment with the three thrombospondin-1 type 1 repeats recombinant protein in an orthotopic human pancreatic cancer model. Clin Cancer Res 11: 2337-2344.

Zhang X, Connolly C, Duquette M, Lawler J, Parangi S. 2007. Continuous administration of the three thrombospondin- 1 type 1 repeats recombinant protein improves the potency of therapy in an orthotopic human pancreatic cancer model. Cancer Lett 247: 143-149.

Zhang X, Kazerounian S, Duquette M, Perruzzi C, Nagy JA, Dvorak HF, Parangi S, Lawler J. 2009. Thrombospondin1 modulates vascular endothelial growth factor activity at the receptor level. FASEB J 23: 3368-3376. 


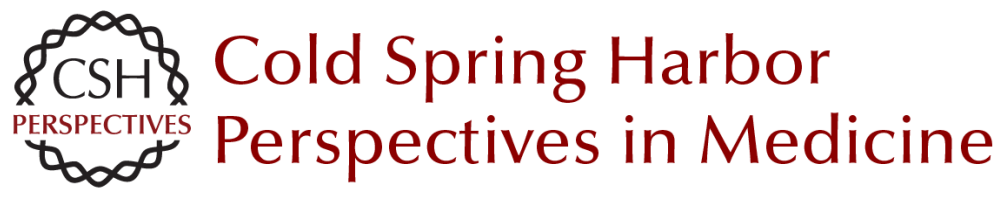

\section{Molecular Basis for the Regulation of Angiogenesis by Thrombospondin-1 and -2}

Patrick R. Lawler and Jack Lawler

Cold Spring Harb Perspect Med 2012; doi: 10.1101/cshperspect.a006627 originally published online January 31, 2012

Subject Collection Angiogenesis

Extracellular Matrix Regulation of Vascular

Morphogenesis, Maturation, and Stabilization George E. Davis and Scott S. Kemp

Endothelial Cell-Pericyte Interactions in the

Pathogenesis of Cerebral Cavernous

Malformations (CCMs)

Wang Min and Jenny Huanjiao Zhou

Lymphatic Clearance and Pump Function Jerome W. Breslin

Platelets and (Lymph)angiogenesis Harvey G. Roweth and Elisabeth M. Battinelli

Modeling Brain Vasculature Immune Interactions In Vitro

Ruth Lyck, Hideaki Nishihara, Sidar Aydin, et al.

Human Endothelial Colony-Forming Cells Juan M. Melero-Martin

The Beauty and Complexity of Blood Vessel Patterning

Victoria L. Bautch and Yoh-suke Mukouyama

Endothelialitis, Microischemia, and

Intussusceptive Angiogenesis in COVID-19

Steven J. Mentzer, Maximilian Ackermann and

Danny Jonigk
Regulation of the Blood-Brain Barrier in Health and Disease

Cara C. Rada, Kanako Yuki, Jie Ding, et al.

Targeting Angiogenesis via Resolution of Inflammation

Abigail G. Kelly and Dipak Panigrahy

Notch Signaling in the Vasculature: Angiogenesis and Angiocrine Functions

Sana S. Hasan and Andreas Fischer

Signal Transduction and Gene Regulation in the

Endothelium

Michel V. Levesque and Timothy Hla

Buttons and Zippers: Endothelial Junctions in

Lymphatic Vessels

Peter Baluk and Donald M. McDonald

Endothelial Cell Fate Determination: A Top Notch Job in Vascular Decision-Making

L.A. Naiche, Stephanie R. Villa and Jan K. Kitajewski

Leukocyte Trafficking in Lymphatic Vessels Aline Bauer, Hazal Tatliadim and Cornelia Halin

Lymphatic Tissue and Organ Engineering for In Vitro Modeling and In Vivo Regeneration Anna M. Kolarzyk, Gigi Wong and Esak Lee

For additional articles in this collection, see http://perspectivesinmedicine.cshlp.org/cgi/collection/ 